\title{
Nueve cuentos acerca de mujeres en situación de acoso, hostigamiento $\mathrm{y}$ feminicidio
}

\section{Nine stories talking about sexual harassment and femicide.}

Ma. del Carmen Dolores Cuecuecha Mendoza Universidad Autónoma de Tlaxcala ccuecuecha@yahoo.com.mx

[...] el tema teórico, ético y jurídico de los feminicidios es semejante al gran tema del Holocausto y sus dilemas: ambos crimenes son patrimonio, aprendizaje y lección que pertenece a la humanidad toda. Ni se encuentran sus perpetradores fuera de un horizonte de humanidad común, ni están sus victimas dotadas de una cualidad esencial e idiosincrática que las distinga de todos los otros pueblos masacrados de la historia. Las condiciones históricas que nos transforman en monstruos o cómplices de los monstruos nos acecha a todos. La amenaza de la "monstruificación" pende sobre todos, sin excepción, asi como la amenaza de la victimización. Basta establecer una frontera 
rigurosa y precisa entre un "nosotros" y un

"los otros" y el proceso estará en marcha".

Rita Laura Segato (2016: 52)

Resumen

En México, la violencia de género es una realidad constante y alarmante, prueba de ello son los numerosos casos de asesinatos contra las mujeres por el solo hecho de serlo. El feminicidio, como máxima expresión de la violencia de género que ejerce el patriarcado en contra de las mujeres con la finalidad de someterlas a su ley, es precedido por una serie de actos atroces que solo revelan el odio y desprecio hacia lo femenino. En este artículo se analizan nueve cuentos de autoras mexicanas, cuyas protagonistas reafirman la triste realidad de vivir en un país donde prevalece el orden patriarcal y subyace la ley masculina que las devora y desecha como objetos sin valor. No obstante, concluimos que para cambiar paulatinamente este orden, requerimos educarnos todos -hombres y mujeres- en la equidad de género, en la construcción de nuevas masculinidades libres de violencia y en el respeto al otro.

Palabras clave: violencia de género, feminicidio, patriarcado, equidad, masculinidades

\section{Abstract}

In Mexico, gender violence has become a growing and alarming issue. A direct evidence of this is crime involving the violent and deliberate killing of a woman on the mere fact of being a woman. Femicide, as the highest level of gender violence against women from a patriarchy system having as purpose women subjugation, is preceded by a series of atrocious treatments revealing hate and scorn for women. In this article, we will analyze nine stories written by Mexican women, whose protagonists denounce the sad reality of a country where a patriarchy 
system is widespread concealing women as useless objects. Nevertheless, we conclude we all need to change this little by little. We must educate ourselves -women and men- following gender equity principles, new male conceptions free from violence, based on respect for others.

Keywords: Gender violence, Femicide, Patriarchy, Gender equity, New male conceptions.

Recibido: 3 de septiembre de 2019

Aceptado: 12 de marzo de 2020 https://dx.doi.org/10.15174/rv.vi26.502

$\mathrm{F}^{\text {n la última década, los asesinatos contra las mujeres han au- }}$ Ementado de manera alarmante en México. ${ }^{1}$ Los diarios, la televisión, radio y las redes sociales reportan cada día los numerosos casos de secuestro, desapariciones forzadas y violaciones de mujeres y niñas. Son aterradoras las noticias que anuncian el hallazgo de cuerpos de mujeres con señales de tortura o descuartizados, muchas veces contenidos en bolsas negras para la basura o arrojados en terrenos baldíos o desagües. El mensaje es claro: vivimos en una sociedad patriarcal que odia, desprecia y mata a las mujeres por el simple hecho de serlo. Además, la mayoría de los casos no son esclarecidos, por lo que no hay castigo para los culpables y reina un clima de impunidad e inseguridad para las mujeres que habitan este país. Para ellas, el peligro está en todos lados: en el hogar, en el campus de la universidad, en el trabajo, en el café o en un taxi. El miedo es justificado porque México no es un lugar seguro para los millones de mujeres que lo pueblan.

${ }^{1}$ Como lo menciona Sergio González Rodríguez: "México es el segundo país con más crímenes en contra de las mujeres después de Brasil” (2015). 
La literatura no escapa a esta realidad. Comprometidas con su entorno social, las letras de nuestro país dan cuenta de la situación que viven las mujeres en México. Por eso, el libro El silencio de los cuerpos. Relatos sobre feminicidios (2015), compilado por Sergio Rodríguez González, reúne nueve cuentos escritos por narradoras mexicanas jóvenes, que por experiencia conocen el miedo que vive una mujer. Los nueve relatos detallan desde una voz narradora de mujer el acoso, hostigamiento y secuestro, así como la violación, desaparición y muerte que sufren las protagonistas que transitan en los espacios más peligrosos de México: Ciudad Juárez, Michoacán, Guerrero, Guadalajara y Ciudad de México, por citar algunos de los estados del país en donde se registra más violencia en contra de las mujeres (sin que con esto queramos decir que en los demás estados no exista la violencia contra ellas); en estos espacios geográficos, las mujeres son violentadas por una sociedad patriarcal que las depreda. Las protagonistas provienen de distintos estratos sociales y económicos, así como de edades, lo que demuestra que no solo corren riesgo las jóvenes o las niñas, sino también las de edad madura. El hecho es mostrar que se les asesina por ser mujeres y que ningún espacio, ya sea público o privado, es seguro.

Para Jane Caputi y Diana Russell (1992) la violencia contra las mujeres es un terrorismo sexual que contempla todas las formas de coacción que emplea el patriarcado para inhibir la libertad femenina y presionar a las mujeres a permanecer en el lugar asignado a su género en este orden dominado por hombres o patriarcado, ${ }^{2}$

${ }^{2}$ El patriarcado es un sistema político, una institución que legitima la superioridad sexista de los varones sobre las mujeres, constituyendo así una estructura que opera como mecanismo de dominación ejercido sobre ellas, basándose en una fundamentación biologicista. Esta ideología, por un lado, se construye tomando las diferencias biológicas entre hombres y mujeres como inherentes y naturales. Y por el otro, mantiene y agudiza estas diferencias postulando una estructura dicotómica de la realidad y del pensamiento. El patriarcado establece 
el cual entienden como la institución que se sustenta en el control del cuerpo y la capacidad punitiva de las mujeres.

El objetivo de este trabajo es describir en los nueve cuentos las diversas formas de violencia o terrorismo sexual que padecen las mujeres mexicanas como consecuencia de habitar en un espacio masculino, siguiendo las aportaciones teóricas del feminismo y de Rita Segato acerca del feminicidio.

\section{Violencia y feminicidio}

La violencia está ligada con el poder, con el género que ha ostentado el poder durante siglos; lo masculino es sinónimo de poder. Las manifestaciones de violencia contra las mujeres son formas de retener y reproducir el poder. Es decir, la violencia se encuentra

vinculada a la desigual distribución del poder y a las relaciones asimétricas que se establecen entre varones y mujeres en nuestra sociedad, que perpetúan la desvalorización de lo femenino y su (consecuente) subordinación a lo masculino. Lo que diferencia a este tipo de violencia de otras formas de agresión y coerción es que el factor de riesgo o de vulnerabilidad es el solo hecho de ser mujer (Rico, 1994).

La violencia de género puede adoptar diversas formas, lo que permite clasificar el delito, de acuerdo con la relación en que ésta se enmarca y el ejercicio de poder que supone, en las siguientes

una estructura de poder que está presente en diversas instituciones sociales con el fin de mantener los principios del patriarcado; instituciones como la escuela, el sistema penitenciario, el derecho, la religión, la economía y la cultura. Lucrecia Vacca y Florencia Coppolecchia, "Una Crítica Feminista al Derecho a partir de la noción de Biopoder De Foucault”. Páginas de Filosofía, Año XIII, No 16 (2012), pp. 60-75. 
categorías: violación sexual e incesto, asedio sexual en el trabajo y en las instituciones de educación, violencia sexual contra mujeres detenidas o presas, actos de violencia contra las mujeres desarraigadas, tráfico de mujeres y violencia doméstica (Rico,1994).

Ahora bien, la máxima expresión de la violencia contra las mujeres es el feminicidio - de su traducción del inglés femicide-, ${ }^{3} \mathrm{Dia}-$ na Russel y Jill Radford indican: "pensamos que el feminicidio es la palabra que mejor describe los asesinatos de mujeres por parte de los hombres, motivados por el desprecio, el odio, el placer o el sentido de propiedad sobre ellas" (Fernández, 2012: 50). ${ }^{4}$

Marcela Lagarde coincide con el concepto de Russel y añade desde la visión antropológica que:

[Feminicidio] es el genocidio contra las mujeres y sucede cuando las condiciones históricas generan prácticas sociales que permiten atentados contra la integridad, la salud, las libertades y la vida de

${ }^{3}$ En la década de los noventa, feministas anglosajonas introdujeron el concepto. Aunque femicide, argumenta Diana Russell, "ha estado en uso desde hace más de dos siglos y apareció por primera vez en la literatura en A Satinical Vliuw of London (Inglaterra, 1801) para denominar el asesinato de una mujer" (Atencio, 2011: 2).

${ }^{4}$ El patriarcado es un sistema político, una institución que legitima la superioridad sexista de los varones sobre las mujeres, constituyendo así una estructura que opera como mecanismo de dominación ejercido sobre ellas, basándose en una fundamentación biologicista. Esta ideología, por un lado, se construye tomando las diferencias biológicas entre hombres y mujeres como inherentes y naturales. Y por el otro, mantiene y agudiza estas diferencias postulando una estructura dicotómica de la realidad y del pensamiento. El patriarcado establece una estructura de poder que está presente en diversas instituciones sociales con el fin de mantener los principios del patriarcado; instituciones como la escuela, el sistema penitenciario, el derecho, la religión, la economía y la cultura. Lucrecia Vacca y Florencia Coppolecchia, "Una Crítica Feminista al Derecho a partir de la noción de Biopoder De Foucault”. Páginas de Filosofía, Año XIII, No 16 (2012), pp. 60-75. 
las mujeres. Todos tienen en común que las mujeres son usables, prescindibles, maltratables y desechables. Y desde luego, todas coinciden en su infinita crueldad y son, de hecho, crímenes de odio contra las mujeres (Apud. Fernández, 2012: 49).

Jane Caputi y Diana Russel precisan todas las formas de violencia a las que son susceptibles las mujeres hasta llegar al asesinato:

El feminicidio representa el extremo de un continum de terror anti femenino e incluye una amplia variedad de abusos verbales y físicos, tales como la violación, tortura, esclavitud sexual (particularmente por prostitución), abuso sexual infantil incestuoso o extra familiar, golpizas físicas y emocionales. Acoso sexual (por teléfono, en las calles, las oficinas y en el aula), mutilación genital (clitoridectomías, escisión, anfibulaciones), operaciones ginecológicas desnecesarias (histerectomías gratuitas), heterosexualidad forzada, esterilización forzada, maternidad forzada (por la criminalización de la contracepción en nombre del embellecimiento). Siempre que estas formas de terrorismo resulten en muerte, ellas se transforman en feminicidios (Apud. Fernández, 2012).

En los diarios aparecen de forma cotidiana todas estas formas de terrorismo sexual como una cortina de humo que invisibiliza o normaliza un ambiente patriarcal que atribuye menor valor a las vidas de las mujeres, por lo que hay una mayor propensión a justificar los crímenes que padecen.

Los feminicidios, como ya hemos mencionado, son crímenes de odio contra las mujeres, son crímenes del patriarcado, es decir, crímenes del poder, cuyo objetivo es la retención y reproducción del poder (Segato, 2006: 4). Por tanto, el feminicidio -siguiendo a Segato- es la consecuencia de la infracción femenina a las dos leyes del patriarcado: la norma del control o posesión sobre el cuerpo 
femenino y la norma de la superioridad masculina. Según estos dos principios, la reacción de odio se desata cuando las mujeres ejercen autonomía en el uso de su cuerpo desacatando reglas de fidelidad o de celibato. Agregaríamos también cuando las mujeres usan atuendos que atentan contra el recato patriarcal o asisten a bares y antros a altas horas de la noche contraviniendo la norma misógina que excluye a las mujeres de esos espacios. Asimismo, otra consecuencia es cuando las mujeres acceden a posiciones de autoridad o poder económico o político, tradicionalmente dominado por los hombres.

Podemos entender entonces que la violencia contra la mujer y su expresión más alta, el feminicidio, son formas de control, de escarmiento, para someter a las otras mujeres por medio del ejemplo, pues el victimario se torna en una especie de paladín de la moral patriarcal que realiza una acción punitiva. Para Laura Rita Segato, el patriarcado reclama el control y competición sobre y con la víctima, así como la acción dirigida a la conservación y reproducción del poder patriarcal.

En este mismo orden de ideas, Ana María Fernández señala que debemos comprender el feminicidio en su dimensión social y política, "en el contexto más amplio de las relaciones de dominio y control masculino sobre las mujeres, relaciones naturalizadas en la cultura patriarcal, en sus múltiples mecanismos de violentar, silenciar y permitir su impunidad" (2012: 48).

En efecto, la impunidad, en la mayoría de los casos de feminicidio, es una constante que Rita Segato considera debe ser interpretada no como consecuencia del feminicidio, sino como productora y reproductora del silencio. La fraternidad o cofradía masculina que devora a las mujeres, sella su pacto de silencio "con la complicidad colectivamente compartida de las ejecuciones horrendas de un pacto de silencio capaz de garantizar la lealtad inviolable de cofradías mafiosas [entiéndase, las instituciones policiacas, los ma- 
gistrados y jueces] un pacto de sangre en la sangre de las víctimas" (2016: 43).

Para Segato, la impunidad de los crímenes de mujeres confirma la alianza de la fraternidad masculina, la cual entiende como una red que articula miembros de la élite económica, de la administración pública y de la justicia locales, provinciales y federales que es capaz de neutralizar la fuerza de la ley que no consigue actuar de forma eficaz. ${ }^{5}$

De esta forma, el patriarcado es una estructura que se convierte en un Segundo Estado que subyace al Estado oficial:

La estrategia clásica del poder soberano para reproducirse es divulgar e incluso espectacularizar el hecho de que está más allá de la ley [...]. Con el importante agregado de que la asociación mafiosa parece actuar en red tentacular con sujetos insertados a la administración oficial en varios niveles, revelándose como un Segundo Estado que controla y da forma a la vida social por debajo del manto de la ley (Segato, 2016: 44).

${ }^{5}$ Rita Segato propone un modelo que explica la forma de proceder del sistema patriarcal en relación a los feminicidios: un eje vertical para vincular el poder con la sujeción, o sea, del perpetrador con su víctima; y un eje horizontal que vincula al perpetrador con sus pares, en una relación que trabaja para mantenerse simétrica. En el caso de los feminicidios de Ciudad Juárez se adapta perfectamente: en el eje horizontal, el eje de la hermandad, de la cofradía, de las corporaciones, involucrada en los negocios ilegales de la región. La mujer es presa del eje horizontal. En este sentido, no es la víctima a quien se dirigen en su discurso de violencia, sino a sus pares, en una demostración de capacidad de muerte y crueldad probada en la víctima, que los habilita a participar en la hermandad mafiosa. En ella se da un pacto de semen, un pacto de sangre en la sangre de la víctima que sella la lealtad de grupo y, con eso, produce y reproduce impunidad (2006: 7). 
Con este panorama aterrador para las mujeres, pero esclarecedor de lo que ocurre en los homicidios cruentos contra éstas y la impunidad que los acompaña, ocasiona una atmosfera de temor e inseguridad para todas, como se recrea en los cuentos que a continuación revisaremos.

\section{Un intento de clasificación}

Los nueve relatos en estudio abordan distintos tipos o grados de violencia contra las mujeres que van desde el acoso, hasta la violación y la muerte. El miedo o temor es consecuencia de vivir en un contexto violento y consideramos que también tiene gradaciones que van del miedo, al pánico o terror extremo a morir asesinada. Por eso, los relatos que proponemos en este análisis los hemos ordenado en tres categorías: por las consecuencias de un ambiente con violencia, por las diversas formas de violencia contra las mujeres y, finalmente, por la idealización del regreso a la vida de las mujeres asesinadas, como veremos a continuación.

\section{Del miedo al terror de vivir en un ambiente de violencia}

En el relato titulado "Sin nombre" de Cristina Rivera Garza (Matamoros, México, 1964), se narra la historia de una mujer de la tercera edad que vive sola en un departamento de una ciudad urbana cualquiera. ${ }^{6} \mathrm{Al}$ ver en la televisión la violencia con la que dos ancianas son estranguladas y descuartizadas la hacen sentir miedo. Las noticias en la televisión describen el hallazgo de los cuerpos encontrados y mutilados la hacen sentir insegura de vivir en un

${ }^{6}$ A partir de este momento los fragmentos del libro en análisis El silencio de los cuerpos. Relatos sobre feminicidios, los citaré solo con el número de página. 
edificio, rodeada de desconocidos, esto le provoca miedo y después pavor y terror.

La narradora protagonista, que se entiende es vecina y cuidadora de la anciana, apunta: "En las noticias seguían dando los mismos noticiarios. Las muertas eran ahora dos mujeres sin nombre, como siempre. Dos mujeres mayores. Evité ver las imágenes, pero escuché el recuento de los hechos. Una persecución. Un hacha en el aire. Un silencio. [...] Las bocas abiertas. Sus dientes apostillados. [les cortaron] Las manos. Las cabezas. Las pantorrillas. Las piernas (18 y 19).

"Estación Cora” de Ivone Reyes Chiquete (México, 1977) también aborda el miedo a una sociedad machista que depreda a las mujeres. El relato narra la historia de una pareja, Rubén y Vanesa, que viaja a Nayarit en compañía de la hija de él, Camila, una niña de 10 ańos. Los tres esperan llegar al pueblo de Cora, donde él trabajó como médico del centro de salud de la localidad. Cora es un pueblo donde la violencia es el común denominador. Violaciones, asesinatos y desapariciones de mujeres acurren cada día, así como las muertes por el tráfico de drogas. En el pueblo reina el caos y los pocos pobladores viven con miedo. Por eso Rita, la mujer de sesenta ańos que los recibe en el pueblo, los insta a que se marchen, pues en la noche no hay seguridad. En un modesto restaurante, un hombre de ojos torvos y lascivos, mira con insistencia a Vanessa y trata de provocar a Rubén para liarse a golpes con él. Por eso, la pareja decide salir de Cora, pero la noche está por caer.

El ambiente de suspenso y tensión que la escritora logra en el relato es excelente. Aunque también muestra una sociedad machista en la que los hombres se disputan las mujeres como un derecho de posesión que se gana con el triunfador de la riña. En un dialogo entre Rita y Rubén, podemos apreciar el clima de inseguridad del pueblo: “- -Tengan cuidado en los retenes en la carretera. Ya no sabe uno si pararse o huir. Si es del ejército, más vale detenerse, 
porque si no le disparan a uno a matar. Pero si es falso, hay que acelerarle porque los cabrones se llevan a las mujeres y nadie las vuelve a ver" (73).

"Réflex" de Abril Posas (Guadalajara, México, 1982) es un relato que aborda el miedo y la melancolía que viven los familiares de una mujer desaparecida. El cuento es narrado por la hija de la ausente: "Un martes de hace catorce meses y dos semanas, mi madre desapareció acompañada solo de su cámara y rollos de veinticuatro fotos a color en una bolsa de tela. Ocho meses y un día atrás, todavía hablaba de ella en presente. Hasta que una tarde me puse a repasar las fotos que guardaba en álbumes y portarretratos" (38).

Fermín, primo político de la desaparecida y encargado de la farmacia donde ella revelaba sus fotos fue el último en verla con vida y el primero en ver las fotos que tomó la mujer. El cuento narra la desolación de la familia y la interminable espera. También sugiere quién fue el asesino: Fermín que era su familiar y amigo -como ocurre usualmente en los casos de desaparecidas, sus victimarios son cercanos a ellas-. Asimismo, muestra un sistema de justicia hecho por y para hombres; por tanto, su ineficiencia justifica el crimen e incita a su reproducción porque hay impunidad.

\section{Hostigamiento, secuestro, violación y muerte}

Esta clasificación corresponde a los relatos en los que se narra la violencia hacia las mujeres en la forma de hostigamiento, acoso, secuestro, violación y, finalmente, la muerte, con la consecutiva desaparición del cuerpo de las víctimas.

Uno de los cuentos más estremecedores es "Bato" de Orfa Alarcón (Nuevo León, México, 1979). El relato está situado en Michoacán y trata acerca de la historia de Bato, una jovencita de 16 años de complexión gruesa que viste como un chico con pantalones de mezclilla abombados y caídos, y calza tenis. Este aspecto 
hace que los jóvenes del barrio donde vive la hostiguen por su orientación sexual. Su forma de vestir contraviene la norma patriarcal de que las mujeres deben usar vestido, zapatillas y esmerarse en su arreglo. Pero Bato es diferente, por lo que una pandilla de tipos rudos la secuestra y, para quitarle su aspecto que ellos llaman de "marimacha", la violan tumultuariamente y, posteriormente, la asesinan. Dice la narradora personaje del relato:

Bato y yo tenemos la misma cara, pero vidas y cuerpos diferentes. Somos hermanas porque nos tocó serlo, no porque tengamos algo que ver. El Wicho me cortó porque dice que de seguro soy marimacha como mi hermana.

—Pásame al Benny_ le digo al Wicho cuando me contesta otra vez.

-Qué, a ti también te gusta la panocha? ¿Quieres que también a ti te lo quitemos a vergazos? - me cuelga (29).

Esta forma de proceder por parte de los pandilleros, muestra las medidas punitivas o correctivas contra Bato, las cuales se pueden considerar una advertencia para las demás. Asimismo, muestra la relación entre pares, cofrades que sellan con semen y sangre la retención y reproducción del poder patriarcal, a la vez que afianza la lealtad de la hermandad masculina (Segato, 2006: 5). La violencia se instaura como un lenguaje patriarcal para Bato, ya que no es permitida su tendencia lesbiana u homosexual, pues para los pandilleros significa desprecio hacia los hombres. La muerte de Bato es la respuesta a la falta a la ley patriarcal de la heterosexualidad obligatoria.

Otro relato más que trata acerca del acoso, la violación y muerte es "Viva" de Raquel Castro (México, 1976). El relato narra la historia de Marisela, una joven de 16 ańos, cuya hermana desaparecida diez años atrás ocasiona sufrimiento en la madre, quien acu- 
de a todos los plantones y marchas que realizan los padres de otras mujeres desaparecidas. Marisela y su madre se mudan a vivir con la hermana de ésta, Leonor, cuyo esposo se ofrece a apoyarlas. Posteriormente, cansada de la depresión de su madre y de acudir a los plantones, Marisela decide quedarse en la casa, sin saber que su tío Rodrigo la acosará y, bajo el efecto de su borrachera, le confesará que asesinó a su hermana, quien insospechadamente se encuentra enterrada en el patio de la casa. Dice Marisela:

La tía Leonor es la que no nos habla. Cuando la policía llegó a escarbar en su jardín dijo que no nos perdonaría nunca, y hasta ahora lo ha cumplido. Yo no sé cuánto sabe ella. Cuánto podría haber sabido, así que no sé si tengo algo que perdonarle o si querría hacerlo.

Ayer enterramos a Sabina. Siento horrible. Siento alivio. Salgo a la escuela, a trabajar, y miro a la gente a la cara. Me llamo Marcela. Me siento viva (159).

Como vemos, el asesino de Sabina estaba en el núcleo familiar ${ }^{7}$ de la víctima y su cuerpo en la misma casa donde vivía con su madre y hermana. Hay que resaltar la actitud cómplice de la tía de la joven secuestrada y esposa del asesino. Una actitud poco solidaria con el género femenino.

"Lapidoserena" de Tania Tagle (México, 1986) relata la historia de una periodista de la ciudad de México que vuela a Ciudad Juárez, Chihuahua, con el propósito de recopilar información que

${ }^{7}$ Los estudios acerca del feminicidio han realizado clasificaciones o tipologías de los homicidios perpetrados contra las mujeres. En el caso de este cuento, se trata de un feminicidio familiar, de acuerdo con Julia Monárrez (Atencio, 2011). Para conocer más sobre los tipos de feminicidio, consúltese el artículo de Graciela Atencio, "Feminicidio-Femicidio: un paradigma para el análisis de la violencia de género". 
le permita escribir acerca de Susana Chávez, una activista gay, asesinada en 1993, y a quien se le adjudica la frase "ni una muerta más":

Imagino a Susana a mediados de los noventa, con veintidós o veintitrés ańos, admitiendo ser gay en una ciudad como ésta [Ciudad Juárez, Chihuahua], donde a la fecha, las manifestaciones públicas de afecto entre homosexuales son motivo de linchamiento. De no haber sido una activista conocida y comprometida [...] que encabezó cientos de protestas en contra del feminicidio en todo el país, hubiera sido sencillo, casi lógico, decir que la mataron por lesbiana (87).

La periodista y narradora de la historia también es gay y encuentra un panorama desalentador para su propósito, ya que -al ser Ciudad Juárez un foco rojo en el tema de asesinatos de mujerescomprueba la ineficacia de las autoridades policiacas y las instituciones que, por medio de la burocracia, se hace cómplice de los asesinos. Aparecen los nombres de Gladis Janeth Guerrero de doce años, Silvia Rivera Morales de 17 y Sagrario González, también de diecisiete, entre cientos de mujeres que fueron asesinadas con el mismo modus operandi: violadas, estranguladas y asesinadas (a estas últimas también les habían cercenado el seno izquierdo). Dice la narradora:

Se debilitó la teoría del asesino solitario y comenzaron a surgir las primeras hipótesis acerca de una organización que ofrecía ritos satánicos y orgías sadomasoquistas a empresarios y políticos en donde se sacrificaba a las muchachas secuestradas. Esto coincidía con el auge de los videos snuff en Estados Unidos y muchos periodistas creyeron encontrar una relación que a la fecha no se ha podido comprobar (85). 
Como sabemos, las muertas de Juárez se han convertido en el modelo de impunidad que cuestiona la eficacia del sistema de justicia mexicano. Para Segato, se trata de una cofradía masculina que articula miembros de la élite económica, de la administración pública y de la justicia local, provincial y federal, la cual, como comprueban los ya más de veinte años de impunidad, han sido capaces de neutralizar las fuerzas de la ley.

\section{Discriminación y muerte}

En este apartado clasifico los relatos que abordan el tema de las mujeres que son discriminadas por su ocupación como prostitutas, al punto de que las autoridades justifiquen todo tipo de violencia ejercida en ellas, incluso el feminicidio. Asimismo, se discrimina a las taxistas, oficio que preponderantemente realizan los hombres.

"Las gallas" de Susana Iglesias (Ciudad de México, 1978) es un relato polifónico que es narrado por la voz de prostitutas que sienten el escarnio público a través de groserías e insultos, así como el acoso de las autoridades que las desprecian por su ocupación y, además, les niegan sus derechos a ser tratadas con respeto y dignidad. Cuando son golpeadas brutalmente e incluso asesinadas por las golpizas y/o mutilaciones, las autoridades no resguardan su seguridad, sino que abusan de ellas. Tenemos entonces que son violentadas y discriminadas por ser mujeres y por ser prostitutas. Ellas mismas saben que su oficio es peligroso pues se juegan la vida con cada cliente, saben que las autoridades no investigarán el asesinato de una mujer como ellas:

-Vienes a declarar? Caite primero con dos mil pesos y orita encuentro al culero que te pegó, no te hagas pendeja, seguro quisiste asaltar a un cliente y te madreo tu padrote por pendeja. Acá ya las conocemos a todas, pa' que no digas que somos iguales que el que 
te pegó, te ofrezco una cosa: lo encuentro porque lo encuentro [...] solo dame dos mil pesos y luego lo busco (174).

“Consuelo de tontos” de Iris García Cuevas (Acapulco, México, 1977) narra la violencia y corrupción de la policía del estado de donde es oriunda: Guerrero. El relato aborda la historia de Blanca, una viuda de cuarenta ańos, cuyo esposo fue asesinado en su taxi. Jamás se esclareció el homicidio que ella presenció. La necesidad económica hace que ella trabaje el taxi de su esposo, pero una noche cualquiera la llaman para un viaje y resulta que la pasajera es asesinada en la calle. Inculpan a la taxista. Además, como la pasajera era hija de una magistrada de justicia, Blanca enfrenta el sistema de corrupción del Comandante de policía y del ejército mexicano:

[...] luego pienso que a las teiboleras también las asesinan. Cuatro, ayer; trabajaban en bares, dos eran estudiantes. Ninguna está segura, pero ocupas ser hija de una caca grande para que se investigue. No digo que esté mal, digo que no es parejo. Y al final a ninguna le sirve lo que se haga. Van a quedarse muertas. La cosa son las vivas, y entre esas vivas yo, que no quiero morirme ni por mujer, ni por halcón, ni por taxista (106).

Como advertimos, en estos cuentos es evidente el ambiente patriarcal que ostenta el poder que se articula en las instituciones como el Estado, la policía, el ejército, por mencionar algunas, las cuales están impregnadas de misoginia y desprecio hacia las mujeres, quienes se ven atrapadas, disminuidas e impotentes en un sistema que las somete y controla. 


\section{Un ideal: la vuelta a la vida de las mujeres asesinadas}

Esta última clasificación la considero como un ideal de la escritora en el que se trasluce el deseo de justicia y vindicación hacia las víctimas asesinadas, muchas de ellas anónimas, pues solo se han encontrado sus cuerpos con huellas de tortura.

Un relato interesante, en el que se lee entre líneas la pregunta: ¿Cómo devolvemos a la vida a las tantas mujeres muertas injustamente, unas con nombre y de otras ni eso se sabe, mujeres cuyas vidas fueron truncadas porque se las arrebataron, es el texto "Soñarán en el jardín” de Gabriela Demián Miravete (México, 1979).

El cuento es narrado en dos planos, el factual y el virtual. En el primer plano, el grupo femenil "Las Argüenderas" ${ }^{8}$ se unen para encontrar apoyos y se pueda crear un espacio virtual en el que se traiga a esta vida a todas esas mujeres asesinadas. De esta forma, sus familiares y toda la gente podrá visitarlas y recordarlas, pero también servirá para educar a los hombres ${ }^{9}$ que asistan a visitar el jardín -a manera de cielo- el respeto hacia las mujeres, hacia todas las mujeres:

El plan de Maricela consistía en obtener recursos para construir un memorial que ella diseño junto con Las Argüenderas y otras organizaciones que llevaban el registro confiable de las víctimas. Cada una de las mujeres asesinadas, con su cuerpo y sus nombres, serían replicadas en un holograma tridimensional utilizando testimonios y materiales proporcionados por sus familiares, amigos y,

${ }^{8}$ Hago notar que, según el Diccionario breve de mexicanismos, el apelativo argüenderas alude a las mujeres chismosas: "chismoso", "argüendear: chismosear" (2001: 23). Atributo que culturalmente se le atribuyen peyorativamente a las mujeres.

${ }^{9}$ En efecto, los estudios de género actuales se enfocan en la educación de los hombres para construir masculinidades libres de todo tipo de violencia. 
sobre todo, la información recuperada de sus cuentas personales de correo electrónico y redes sociales, fotografías, videos, cartas y conversaciones. Todo sería útil para recordar de la forma más precisa sus voces, sus movimientos, sus reacciones, para de alguna forma traerlas de nuevo a la vida (127).

\section{Consideraciones finales}

Como hemos comprobado a través de estos nueve cuentos, situados en diversos lugares del territorio mexicano, las mujeres viven en una sociedad patriarcal violenta y agresiva que las asesina para someterlas; sin embargo, la crueldad a la que son sometidas en los momentos previos a su muerte hay que resaltarla, subrayarla y enfatizarla porque nos permite advertir el enorme desprecio y odio que existe hacia las mujeres. Al hacerlo, nos damos cuenta que estos actos son crímenes del patriarcado.

Las mujeres de todas las edades y de todas las clases sociales viven en un universo adverso y peligroso. El miedo y el terror de todas ellas contrasta con la indiferencia de las autoridades y de las instituciones que son cómplices por omisión, ya que no esclarecen los crímenes ni los castigan, lo cual no es de extrańar porque las leyes son hechas por los hombres. Laura Rita Segato señala que

toda violencia es política y la violencia contra las mujeres es la forma más normalizada en la sociedad. El feminicidio es el homicidio político de género y contribuyen a él las comunidades y las instituciones que no hacen lo necesario por construir una cultura de igualdad, por reformar la educación y para respetar las leyes nuevas de igualdad (2006).

Los nueve cuentos, narrados desde voces femeninas, muestran el sentir y pensar de las mujeres en un clima de violencia extrema; 
son cuentos inspirados en la realidad alarmante y vergonzosa que vivimos cada día en un país que no es seguro porque podemos ser secuestradas y desaparecer, así de simple. O bien, aparecer asesinadas y descuartizadas. La realidad, increíblemente, normalizada es que día a día vemos circular, en los chats y en las redes sociales, solicitudes para compartir la foto de una mujer que fue a trabajar o a estudiar y de la cual no se sabe su paradero. Presentimos que su suerte es incierta, pero sabemos que la imaginación no alcanza a adivinar el horror que está pasando.

Todo esto nos hace preguntarnos ¿qué estamos haciendo para cambiar esta realidad? Considero que no hay una sola respuesta, que la solución es integral porque los hombres deben y tienen que cambiar urgentemente y educarse para construir nuevas masculinidades sin violencia, basadas en la equidad y el respeto al otro.

Los padres de familia tenemos que preguntarnos qué estamos formando a las nuevas generaciones y para ello debemos educarnos en la equidad de género para no reproducir en nuestras hijas e hijos los patrones de conducta patriarcales y misóginos.

Las instituciones tienen que educarse en la equidad de género para que en una primera instancia puedan comprender el problema y, por fin, puedan investigar los incontables (sin ser alarmista, pero el número es incierto) asesinatos que ocurren cada día en el país y sancionar a los culpables, pues no puede existir, en un país que se precie de civilizado, la opción de cobijar la impunidad.

Las mujeres estamos cambiando, pero es importante que todos -hombres y mujeres- reflexionemos y llevemos a cabo la política de la sororidad que propone Marcela Legarde la cual "trata de desmontar la misoginia, acción básica para el empoderamiento de las mujeres y la construcción de la igualdad" (2009). 


\section{Bibliografía}

Atencio, Graciela, 2011, "Feminicidio-Femicidio: un paradigma para el análisis de la violencia contra las mujeres", Feminicidio, 4 de marzo. Disponible en:

https://feminicidio.net/sites/default/files/seccion_feminicidio_paper_02.pdf

Fernández, Ana María, 2012, "Femicidios: la ferocidad del patriarcado", Revista Nomadias, núm. 16, Noviembre, pp. 47-73. Disponible en: https://nomadias.uchile.cl/index.php/NO/article/ view/24957

Gómez de Silva, Guido, 2001, Diccionario Breve de mexicanismos de la Academia Mexicana de la Lengua, Fondo de Cultura Económica, México.

González Rodríguez, Sergio, 2015, El silencio de los cuerpos. Relatos sobre feminicidios. Ediciones B, México.

Legarde, Marcela, 2009, "La política de la sororidad", Mujeres en red. El Periódico Feminista, 11 de junio. Disponible en: http://www.mujeresenred.net/spip.php?article1771

Segato, Rita Laura, 2016, "La escritura en el cuerpo de las mujeres asesinadas en Ciudad Juárez. Territorio, soberanía y crímenes de Segundo Estado", en La guerra contra las mujeres, Traficantes de sueños, Madrid. Disponible en: https://www. traficantes.net/sites/default/files/pdfs/map45_segato_web. pdf

, 2006, "Qué es un feminicidio. Notas para un debate emergente", Serie Antropología, núm. 401, Brasilia. Disponible en:https://www.nodo50.org/codoacodo/enero2010/ segato.pdf

Rico, Nieves, 1994, Violencia de género: un problema de derechos humano, ONU/CEPAL. Disponible en: https://repo- 
sitorio.cepal.org/bitstream/handle/11362/5855/S9600674_ es.pdf?s

Vacca, Lucrecia y Florencia Coppolecchia, 2012, "Una Crítica Feminista al Derecho a partir de la noción de Biopoder De Foucault", Páginas de Filosofia, Año XIII, núm. 16, pp. 60-75. 